\title{
Determination of polybrominated diphenyl ethers and metabolites by single-drop microextraction and GC-MS/MS
}

\author{
Yuxin Chen ${ }^{1} \cdot$ Hongtao Liu ${ }^{1}$ (D Jun Peng ${ }^{1} \cdot$ Haiyun Zhou ${ }^{1} \cdot$ Tiangang Luan $^{1,2}$
}

Received: 27 November 2019 / Accepted: 30 March 2020 / Published online: 29 April 2020

(c) Springer Nature Switzerland AG 2020

\begin{abstract}
A simple, fast and virtually solvent-free method for the simultaneous determination of 13 polybrominated diphenyl ethers (PBDEs) congers and their metabolites in aqueous samples was developed using single-drop microextraction (SDME) coupled with gas chromatography-tandem mass spectrometry (GC-MS/MS). Optimization over GC-MS/MS parameters of both electron ionization (EI) and negative chemical ionization $(\mathrm{NCl})$ sources were studied and compared with a result that El is more sensitive and selective, especially for lower brominated congeners. Optimization of SDME was subsequently conducted. Under optimum conditions ( $1 \mu \mathrm{L}$ drop of chlorobenzene in $2 \mathrm{~mL}$ sample solution, $\mathrm{pH}$ 5.0, 30 min extraction time, stirring rate of $400 \mathrm{rpm}$ ), the assay linearity of target PBDEs was confirmed over 2-3 orders of magnitudes, with a coefficient of determination $\left(r^{2}\right)$ ranged from 0.9929 to 0.9998 . The limit of detection (LODs) and limit of quantification (LOQs) for lower brominated congeners were found to be better than $6 \mathrm{ng} \cdot \mathrm{L}^{-1}$ and $20 \mathrm{ng} \cdot \mathrm{L}^{-1}$, respectively. Real sample analysis with an isotopic internal standard was carried out. The recoveries, relative standard deviation (RSD) and enrichment factors obtained ranged from 73.4 to $128.0 \%, 7.52$ to $25.0 \%$ and 8 to 60 , respectively, indicating the developed method is suitable for the determination of PBDE congers in aqueous samples.
\end{abstract}

Keywords GC-MS/MS · Single-drop microextraction (SDME) · Metabolites · Polybrominated diphenyl ethers (PBDEs)

\section{Introduction}

Polybrominated diphenyl ethers (PBDEs) constitutes 209 possible congeners which are widely used as brominated fire retardants in a variety of commercial or household products, such as textiles, plastic, furniture, and electronic components [1]. However, PBDEs may enter the environment through emission from the manufacturing, recycling and disposal processes of these products [2-4]. As lipophilic and persistent chemicals, PBDEs bind strongly to soil, sediments and airborne particulate matter, and tend to accumulate in the environment for years without significant degradation [5]. Also, PBDEs are bio-accumulative and biomagnified in adipose tissues of animals and human, which leads to growing concerns. Toxicology studies have speculated the hazards of PBDEs toward human health in terms of neurotoxicity [6-8], thyrotoxicity [9-11], estrogenicity [12-14], carcinogenicity, [15-17] cellular toxicity $[18,19]$, and cognitive disorder $[20,21]$. In view of the risk of human exposure to PBDEs in the environment, the U.S. EPA have assigned an oral slope factor of $7 \times 10^{-4} \mathrm{mg} /$ $\mathrm{kg} /$ day for carcinogenic risk. Thus, PBDEs have emerged as one of the major environmental pollutants.

\section{Electronic supplementary material The online version of this article (https://doi.org/10.1007/s42452-020-2642-2) contains} supplementary material, which is available to authorized users.

Hongtao Liu, liuht@mail.sysu.edu.cn; $\bowtie$ Tiangang Luan, cesltg@mail.sysu.edu.cn | ${ }^{1}$ Instrumental Analysis \& Research Center, Sun Yat-Sen University, Guangzhou 510275, People's Republic of China. ${ }^{2}$ School of Life Sciences, Sun Yat-Sen, University, Guangzhou 510275, People's Republic of China. 
The congeners of PBDEs show different properties. For instance, lower brominated congeners are more persistent and bioaccumulated in the environment, while higher brominated congeners tend to bind to sediment or soil particles [2]. Therefore, congener-specific analysis is of researchers' interest. To achieve this, the identification and quantification of PBDEs in various kinds of environmental samples are required with specific analytical techniques with high selectivity, sensitivity and precision. Current analytical determination methods are mostly based on gas chromatography for separation of target compounds, coupling with mass spectrometry (GC-MS) for targets detection. More recently, to achieve better selectivity, isotope dilution and internal standard with gas chromatography/high resolution mass spectrometry (GC/HRMS) for samples of water, soil, sediment and tissues were employed in the U.S. EPA Method 1614 [22] to detect PBDEs. Electron ionization (EI) was used as the ionization source in this method, as well as in some other studies [23,24] due to the abundant generation of highly specific molecular ions $\left([\mathrm{M}]^{+*}\right)$ or high-mass fragment ions (i.e. $\left[\mathrm{M}-\mathrm{Br}^{-}\right]^{+}$). However, the use of strong electron energy may lead to a loss of unstable molecular ions. Negative chemical ionization $(\mathrm{NCl})$ as a popular alternate, has been proven to be highly sensitive and selective for the determination of electrophilic molecules such as PBDEs $[25,26]$. Concerns do exist over its specificity because quantification is dominated by non-specific bromide ions ( $[\mathrm{Br}]^{-}, \mathrm{m} / \mathrm{z}$ 79 and 81). Moreover, only ${ }^{13} \mathrm{C}$ isotope labeled PBDEs are commercially available for GC-EI-MS, which makes it difficult to find suitable internal standard for GC-NCI-MS if bromide ions are the only quantification ions. Past studies have compared the use of GC-EI-MS and GC-NCI-MS for PBDEs determination [26-28], but few have investigated the use of a gas chromatography tandem mass spectrometry (GC-MS/MS) which is believed to surpass GC-MS over analytical selectivity and specificity. GC-MS/MS provides adequate precursor and product ion selection that allows identification at trace levels in complicated matrixes. The product ion spectra could eliminate inferences and reduce chemical background noises, which may decrease the detection limit. Thus, the present study utilizes GC coupled with triple quadrupole mass spectrometry and compares the performances of $\mathrm{El}$ and $\mathrm{NCl}$ as ionization sources for congener-specific PBDEs analysis after the optimization of instrumental parameters.

Due to the complicated matrices and the relatively low concentrations of PBDEs in the environment, different sample treatment procedures such as extraction, concentration, cleanup and fractionation may be required accordingly before the final instrumental analysis. For liquid samples, conventional sample treatment employs liquid-liquid extraction [29-31], and solid-phase extraction
[32-35]. Although these extraction techniques were capable for the extraction of PBDEs with a decent recovery, the main drawbacks such as time consuming and highly manipulated procedures, limited their applications. In the present work, the single drop microextraction (SDME) was employed as sample treatment method to be coupled with GC-MS/MS so as to achieve a simple, fast and virtually solvent-free method for PBDEs determination in aqueous samples. SDME is an analytical technique which uses only a small amount of water-immiscible solvent for concentrating analytes from aqueous samples [36]. Because of its advantages over simplicity, low cost and the potential for automation or high-throughput designs, it has been a rapidly developing technique for various applications such as the extraction of volatile organic compounds [37], chlorobenzenes [38], phenols [39, 40] and bisphenol A [41] in aqueous media. Herein, SDME was performed by suspending a drop of organic solvent directly from the tip of a micro-syringe needle, which was immersed in a stirred aqueous solution. The extraction drop was retracted back into the syringe after a prescribed period of time, then it was transferred to GC-MS/MS for further analysis without other apparatuses [42]. Since most PBDEs have high logKow value, SDME would be a suitable extraction method for PBDEs detection in water samples.

This study optimized GC-MS/MS conditions in order to characterize their relative effects on sensitivity and specification. The performances of $\mathrm{El}$ and $\mathrm{NCl}$ ionization sources for congener-specific analysis were compared. Direct immersion SDME was performed to extract PBDEs from aqueous samples. The operation parameters were optimized to achieve higher enrichment factors that consequently allowed better sensitivity. Analysis of real samples were conducted based on the optimized conditions and satisfied results were obtained for 8 PBDEs, 3 methylated PBDEs and 2 hydroxylated PBDEs.

\section{Materials and methods}

\subsection{Reagents and apparatus}

Standards of PBDEs and metabolites (details in Table 1) were purchased from AccuStandard (New Haven, CT, USA, 99.9\% for BDE209 and the rest of PBDEs with concentration of $50 \mathrm{mg} \cdot \mathrm{L}^{-1}$ in hexane). The internal standard, ${ }^{13} \mathrm{C}$ labeled $2,2^{\prime}, 3,4,4^{\prime}, 5$-Hexabromodiphenylether $\left(\left({ }^{13} \mathrm{C}_{12}\right)\right.$ BDE138), was purchased from Cambridge Isotope Laboratories (Tewksbury, MA, USA). Chromatographic grade n-hexane, methanol and acetone, were from Burdick \& Jackson (Muskegon, MI, USA), CNW Technologies (Düsseldorf, Germany) and Merck (Darmstadt, Germany), respectively. Analytical grade chlorobenzene, toluene, 
Table 1 GC retention time, ion pairs and optimum El parameters of target PBDE congeners

\begin{tabular}{|c|c|c|c|c|c|c|c|c|c|}
\hline \multirow[t]{2}{*}{ PBDE congeners } & \multirow{2}{*}{$\begin{array}{l}\text { Retention time } \\
\text { (min) }\end{array}$} & \multicolumn{4}{|l|}{ Pair I } & \multicolumn{4}{|l|}{ Pair II } \\
\hline & & $\begin{array}{l}\text { Precursor ions } \\
(\mathrm{m} / \mathrm{z})\end{array}$ & $\begin{array}{l}\text { Product ions } \\
(\mathrm{m} / \mathrm{z})\end{array}$ & $\begin{array}{l}\text { Electron } \\
\text { energy }(\mathrm{eV})\end{array}$ & $\begin{array}{l}\text { Collision } \\
\text { energy } \\
\text { (V) }\end{array}$ & $\begin{array}{l}\text { Precursor ions } \\
(\mathrm{m} / \mathrm{z})\end{array}$ & $\begin{array}{l}\text { Product ions } \\
(\mathrm{m} / \mathrm{z})\end{array}$ & $\begin{array}{l}\text { Electron } \\
\text { energy }(\mathrm{eV})\end{array}$ & $\begin{array}{l}\text { Collision } \\
\text { energy } \\
\text { (V) }\end{array}$ \\
\hline $\begin{array}{l}\text { 2,4,4'-Tribromodiphenyl } \\
\text { ether (BDE28) }\end{array}$ & 5.57 & 406 & 246 & 65 & 17 & 406 & 299 & 65 & 19 \\
\hline $\begin{array}{l}\text { 2'-hydroxy-2,4,4'- } \\
\text { Tribromodiphenyl } \\
\text { ether (2'-OH-BDE28) }\end{array}$ & 6.62 & 424 & 264 & 65 & 17 & 424 & 236 & 65 & 21 \\
\hline $\begin{array}{l}\text { 2'-methoxy-2,4,4'- } \\
\text { Tribromodiphenyl } \\
\text { ether (2'-MeO-BDE28) }\end{array}$ & 6.67 & 436 & 342 & 65 & 19 & 436 & 276 & 65 & 13 \\
\hline $\begin{array}{l}\text { 2,2',4,4'-Tetrabromodi- } \\
\text { phenyl ether (BDE47) }\end{array}$ & 7.21 & 486 & 326 & 65 & 18 & 486 & 245 & 65 & 37 \\
\hline $\begin{array}{l}\text { 3-hydroxy-2,2',4,4'- } \\
\text { Tetrabromodiphenyl } \\
\text { ether (3-MeO-BDE47) }\end{array}$ & 8.99 & 516 & 356 & 65 & 19 & 516 & 341 & 65 & 31 \\
\hline $\begin{array}{l}\text { 2,2',4,4',6-Pentabromodi- } \\
\text { phenyl ether (BDE100) }\end{array}$ & 9.09 & 566 & 406 & 65 & 17 & 566 & 484 & 65 & 13 \\
\hline $\begin{array}{l}\text { 3-hydroxy-2,2',4,4'- } \\
\text { Tetrabromodiphenyl } \\
\text { ether (3-OH-BDE47) }\end{array}$ & 9.33 & 502 & 342 & 65 & 18 & 342 & 262 & 65 & 21 \\
\hline $\begin{array}{l}2,2^{\prime}, 4,4^{\prime}, 5 \text {-Pentabromodi- } \\
\text { phenyl ether (BDE99) }\end{array}$ & 9.76 & 566 & 406 & 65 & 21 & 566 & 486 & 65 & 13 \\
\hline $\begin{array}{l}\text { 6'-methoxy-2,2',4,4'5- } \\
\text { Pentabromodiphenyl } \\
\text { ether (6'-MeO-BDE99) }\end{array}$ & 11.35 & 596 & 436 & 65 & 23 & 596 & 502 & 65 & 21 \\
\hline $\begin{array}{l}2,2^{\prime}, 4,4^{\prime}, 5,6^{\prime} \text {-Hexabro- } \\
\text { modiphenyl ether } \\
\text { (BDE154) }\end{array}$ & 11.92 & 644 & 484 & 65 & 18 & 484 & 404 & 65 & 25 \\
\hline $\begin{array}{l}2,2^{\prime}, 4,4^{\prime}, 5,5^{\prime}-\text { Hexabro- } \\
\text { modiphenyl ether } \\
\text { (BDE153) }\end{array}$ & 13.15 & 644 & 484 & 65 & 20 & 484 & 406 & 65 & 25 \\
\hline $\begin{array}{l}2,2^{\prime}, 3,3^{\prime}, 4,4^{\prime} 6,6^{\prime} \text {-octa- } \\
\text { bromodiphenyl ether } \\
\text { (BDE197) }\end{array}$ & 16.86 & 642 & 533 & 65 & 40 & 802 & 642 & 65 & 33 \\
\hline $\begin{array}{l}2,2^{\prime}, 3,3^{\prime}, 4,4^{\prime} 5,5^{\prime} 6,6^{\prime} \text {-deca- } \\
\text { bromodiphenyl ether } \\
\text { (BDE209) }\end{array}$ & 20.76 & 800 & 642 & 65 & 46 & 958 & 800 & 65 & 17 \\
\hline$\left({ }^{13} C_{12}\right) B D E 138$ & 14.78 & 656 & 496 & 65 & 20 & 496 & 416 & 65 & 25 \\
\hline
\end{tabular}

xylene, cyclohexane, sodium chloride, sulfuric acid and sodium hydroxide were supplied by the Guangzhou Chemical Reagent Factory (Guangzhou, China).

Except for BDE154, BDE153, BDE197 and BDE209, individual stock standard solutions $\left(1 \mathrm{mg} \cdot \mathrm{L}^{-1}\right)$ of each target compound were prepared in hexane. The $100 \mathrm{mg} \cdot \mathrm{L}^{-1}$ stock solution of BDE209 was prepared by dissolving $1 \mathrm{mg}$ of the standard with hexane in a $10 \mathrm{~mL}$ volumetric flask. A mixed-standard solution of all target compounds with different concentrations were prepared by diluting the above stock solution in acetone (BDE28, BDE47, 2'-OH-BDE28, 2'-MeO-BDE28 and 3-MeOBDE47: $10 \mu \mathrm{g} \cdot \mathrm{L}^{-1}$; 3-OH-BDE47, 6'-MeO-BDE99, BDE100 and BDE99: $100 \mu \mathrm{g} \cdot \mathrm{L}^{-1}$; BDE154, BDE 153 and BDE197: $1 \mathrm{mg} \cdot \mathrm{L}^{-1}$; BDE209: $\left.10 \mathrm{mg} \cdot \mathrm{L}^{-1}\right)$. The working standard solutions were freshly prepared by diluting the mixedstandard solution in ultra-pure water, spiked with the internal standard at a concentration of $100 \mu \mathrm{g} \cdot \mathrm{L}^{-1}$.
Ultra-pure water was supplied by Milli-Q apparatus from Merck Millipore (Darmstadt, Germany).

\subsection{GC-EI-MS/MS and GC-NCI-MS conditions}

A Thermo Fischer Trace 1310-TSQ Quantum XLS Gas Chromatography-Triple Quadrupole Mass Spectrometer (GC-MS/MS), with a TG-5HT GC column $(15 \mathrm{~m} \times 0.25 \mathrm{~mm}$ I.D. $\times 0.1 \mu \mathrm{m}$ ) was employed. The GC injection port was set as the splitless mode for $0.8 \mathrm{~min}$, holding isothermally at $280{ }^{\circ} \mathrm{C}$. The injection volume was $1 \mu \mathrm{L}$. High purity helium $(99.99 \%)$ was used as the carrier gas at a flow rate of $1.5 \mathrm{~mL} \cdot \mathrm{min}^{-1}$ under the constant flow rate mode. The temperature program was set as follows: $120^{\circ} \mathrm{C}$ isothermal for $2 \mathrm{~min}, 30^{\circ} \mathrm{C} \cdot \mathrm{min}^{-1}$ to $200{ }^{\circ} \mathrm{C}, 3{ }^{\circ} \mathrm{C} \cdot \mathrm{min}^{-1}$ to $230{ }^{\circ} \mathrm{C}, 40^{\circ} \mathrm{C} \cdot \mathrm{min}^{-1}$ to $300{ }^{\circ} \mathrm{C}$, and $300^{\circ} \mathrm{C}$ isothermal for $6 \mathrm{~min}$. When GC-MS/MS was operated with El source, the selected reaction monitoring (SRM) mode was used, 
with a source temperature of $300^{\circ} \mathrm{C}$, electron energy of $65 \mathrm{eV}$, collision energy of 13-46 V. When operated with $\mathrm{NCl}$ source, selected ion monitoring (SIM) mode was conducted, with a source temperature at $200{ }^{\circ} \mathrm{C}$, electron energy of $70 \mathrm{eV}$, methane as the reaction gas at a constant flow rate of $2.7 \mathrm{~mL} / \mathrm{min}$. Masses of the characteristic ions and the brominated ions for each congener were monitored according to the ionization sources. Identification of each congener was based on the selected $\mathrm{m} / \mathrm{z}$ values determined and characterized experimentally, at the corresponding retention time (details in Table 1). Internal standard calibration was used for quantification of target compounds.

\subsection{Procedure of single-drop microextraction}

The SDME procedure followed the proposed method by Jeannot and Cantwell [42]. The optimized SDME procedure was as follows: in a $2 \mathrm{~mL} \mathrm{GC}$ vial, a $1 \mu \mathrm{L}$ drop of chlorobenzene suspended from the tip of a GC micro-syringe needle was immersed in a $2 \mathrm{~mL}$ sample solution which was previously adjusted to $\mathrm{pH} 5.0$, at a constant stirring rate of $400 \mathrm{rpm}$. After $30 \mathrm{~min}$, the extraction solvent was withdrawn back into the micro-syringe, and then be directly injected to GC-MS/MS for further analysis.

\section{Results and discussion}

\subsection{Optimization of GC-EI-MS/MS and GC-NCI-MS conditions}

Due to the fact that the sensitivities of different compounds differ, 'normalized response' was calculated and used to interpolate the optimization procedure so that the responses for all the compounds can be brought into the same scale. For the same target compound, normalized response was calculated by dividing peak area of selected ion pair in an individual condition by the maximum peak area within the same optimization procedure. It was used for the SDME optimization as well.

\subsubsection{Selection of ion pairs}

Both $\mathrm{El}$ and $\mathrm{NCl}$ sources are capable for the determination of PBDEs. Nevertheless, $\mathrm{NCl}$ could not deliver product ion spectra for PBDEs detection since only fragment ions $[\mathrm{Br}]^{-}(\mathrm{m} / \mathrm{z} 79$ and 81$)$ and $\left[\mathrm{HBr}_{2}\right]^{-}(\mathrm{m} / \mathrm{z} 159,161$ and 163 ) meet the criteria peak intensity (Supplementary Fig. S1 b)), but bromine ions could not deliver further fragmentation, thus the product ion spectra was not feasible for $\mathrm{NCl}$. When operated with $\mathrm{El}$, precursor ions are either molecular ions $[\mathrm{M}]^{+}$or fragment ions with the loss of two bromine atoms $\left[\mathrm{M}-\mathrm{Br}_{2}\right]^{+}$(Fig. S1 a)). Two ion-pairs were selected for each target congener, according to their relative abundances (Table 1).

\subsubsection{Optimization of El conditions}

Since the ionization potential of most organic compounds is about 7-15 eV, the El electron energy of $70 \mathrm{eV}$ is sufficient to generate plenty of fragments, but risking a loss of molecular ions or high-mass fragments which are often selected as precursor ions. Tuning down the electron energy could increase the abundance of these precursor ions and consequently enhance the intensity of product ions. Therefore, the electron energy was optimized between 35 and $70 \mathrm{eV}$ (Fig. $1 \mathrm{a}$ and b). Results show that responses of lower brominated congeners fluctuate mildly between 35 and $65 \mathrm{eV}$ due to the stabilities of their molecular ions within this range. The electron energy over $65 \mathrm{eV}$ leads to a loss of response for most target congeners. Best ionization efficiency for most target congeners was achieved at $65 \mathrm{eV}$. An improvement of ionization efficiency for higher brominated congeners was observed when operated at $70 \mathrm{eV}$, indicating the increasing stability with more bromine substituents. Hence, for compromise, the electron energy was set to $65 \mathrm{eV}$ for further study.

Due to the high boiling point of PBDEs $\left(310-425^{\circ} \mathrm{C}\right)$, the ionization efficiency could be affected by the source temperature of El. Thus, the influence of source temperature from 200 to $300^{\circ} \mathrm{C}$ on ionization intensity was investigated. Seeing from Fig. 1c, significant improvement of intensity was observed with the increasing source temperature. Due to the limitation of the instrument itself, $300^{\circ} \mathrm{C}$ was selected as source temperature.

To generate product ions from the precursor ions in the collision cell, helium was introduced with a certain pressure. The optimization of collision energy for each precursor was carried out to improve the sensitivity (details in Table 1).

\subsubsection{Optimization of reaction gas flow rate for $\mathrm{NCl}$}

Methane was used as the reaction gas. In order not to interfere the high vacuum, the flow rate of methane was optimized within the range of $1.5-2.7 \mathrm{~mL} / \mathrm{min}$ to improve ionization. Results demonstrate enhancing responses for most congeners with increasing flow rate (Fig. 2). Nevertheless, a slight decrease on the ionization intensity for higher brominated congeners was observed. For further $\mathrm{NCl}$ analysis, optimum flow rate was fixed at $2.7 \mathrm{~mL} / \mathrm{min}$. 
(a)

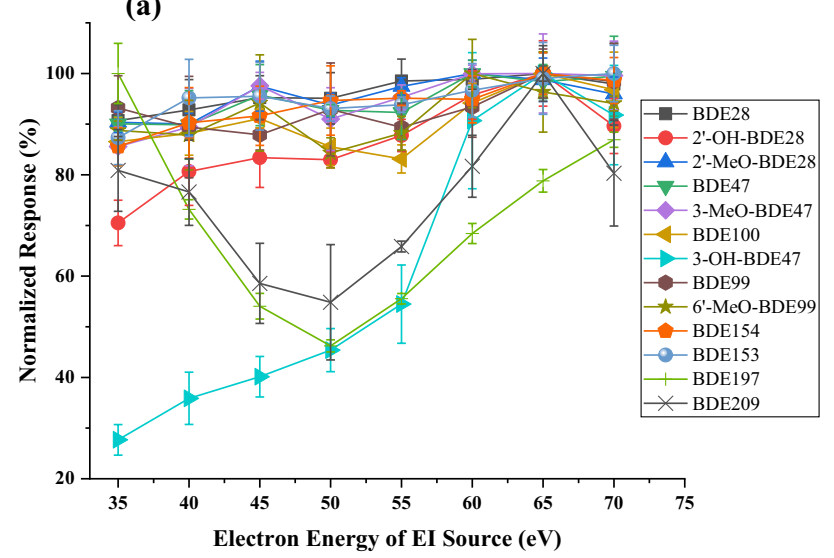

(b)

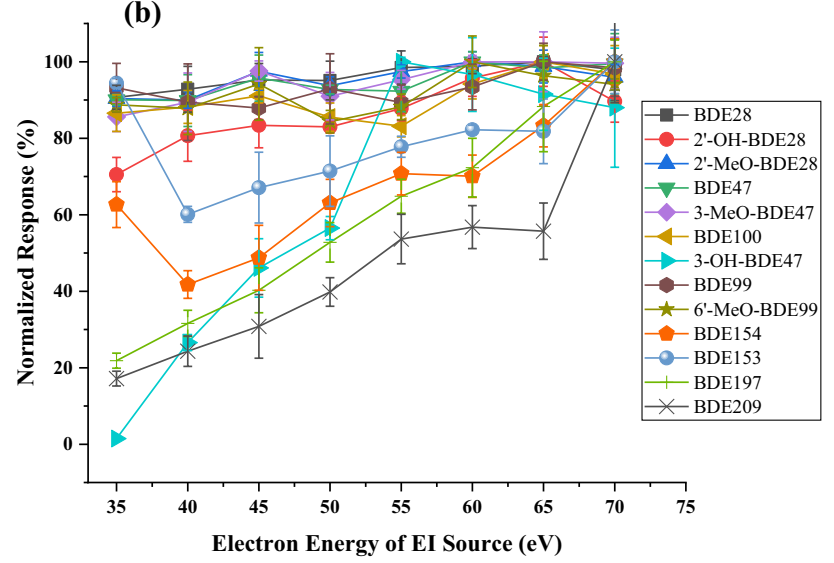

(c)

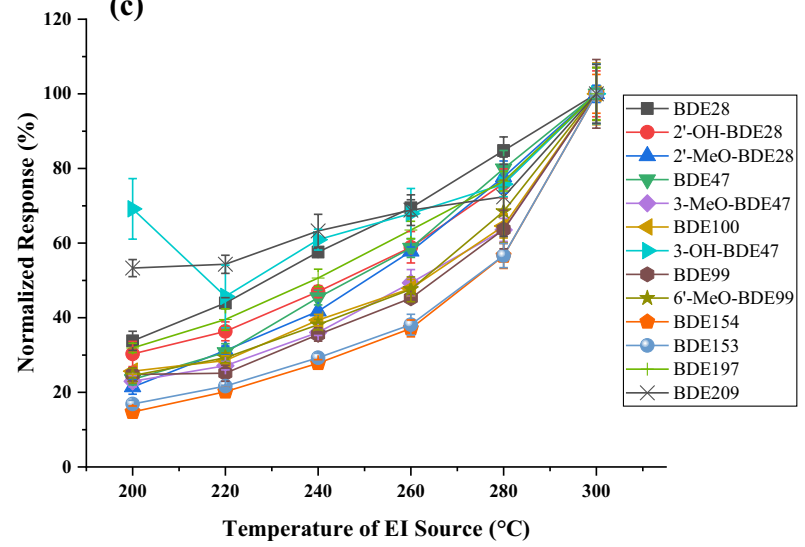

Fig. 1 Effects of El conditions on ion intensity, a electron energy (the first pair of ions); $\mathbf{b}$ electron energy (the second pair of ions); $\mathbf{c}$ source temperature (using mix-standard solution)

\subsection{Comparison of El with $\mathrm{NCl}$}

The comparison of GC-EI-MS/MS and GC-NCI-MS was conducted under the above optimum conditions (Fig. 3). It can be seen that for GC-EI-MS/MS, better performances in terms of peak area and $\mathrm{S} / \mathrm{N}$ ratios are found for penta- or lower brominated congeners while GC-NCI-MS, gaining

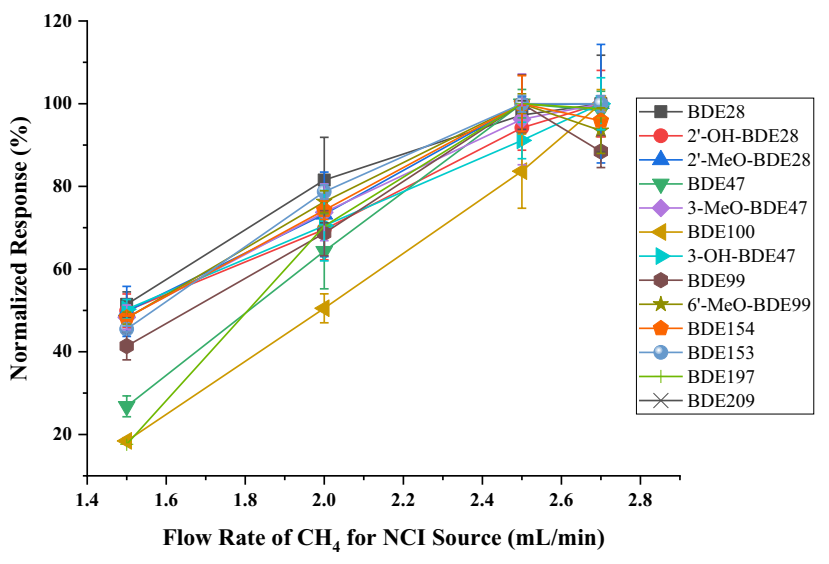

Fig. 2 Effects of methane flow rate on ionization intensity
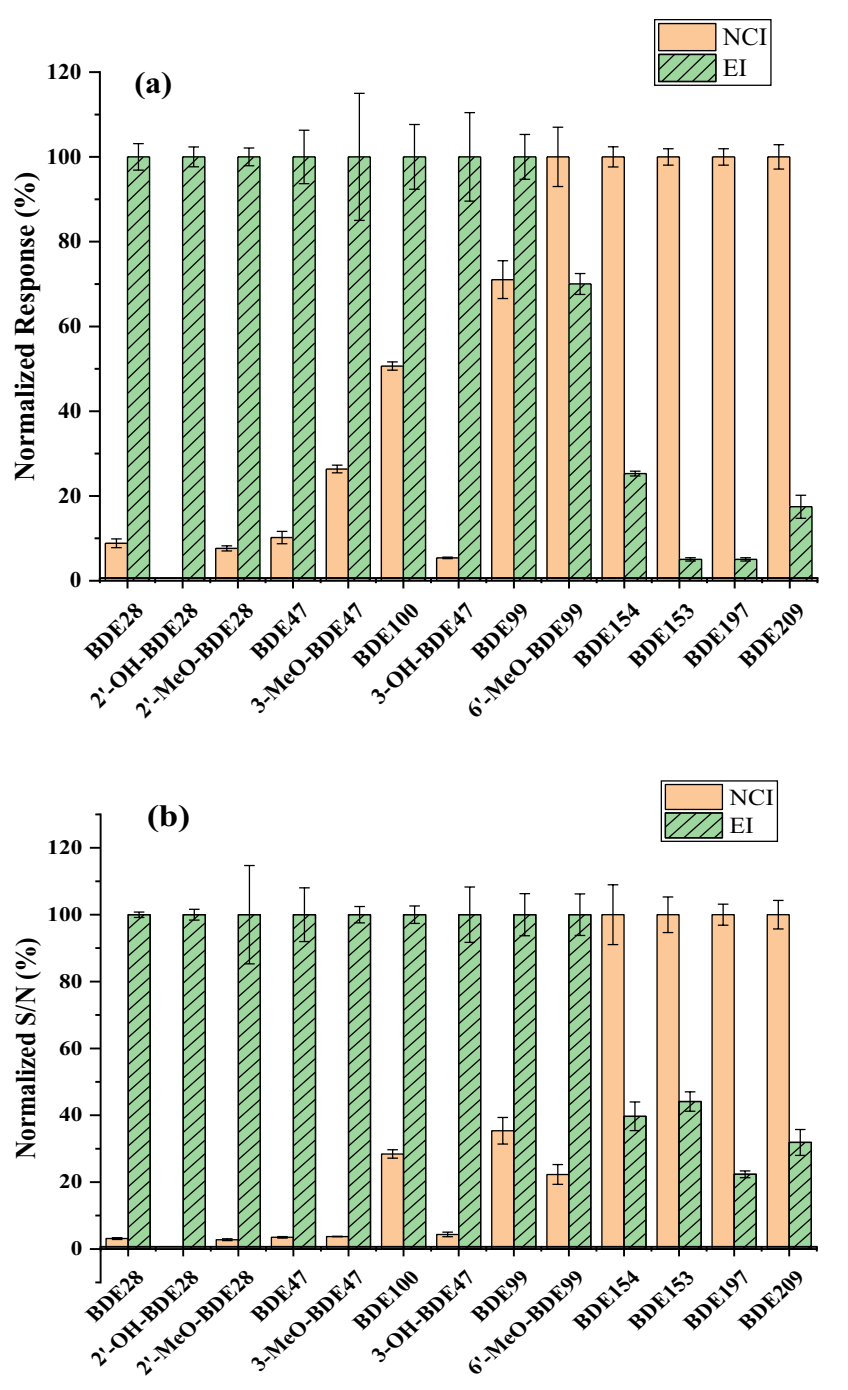

Fig. 3 Comparison of $\mathrm{El}$ and $\mathrm{NCl}$ for $\mathbf{a}$ normalized peak area and $\mathbf{b}$ normalized $\mathrm{S} / \mathrm{N}$ ratio for target PBDE congeners and metabolites 
from its specificity for brominated species, delivers significant increase in sensitivity for higher brominated congeners. This opposite pattern is a consequence of the different fragmentation schemes. El provides certain ionization energy that does not distinct between congeners. Hence, to compromise the major congeners, the sensitivity of higher brominated congeners would be sacrificed. $\mathrm{NCl}$, on the other hand, focuses on the bromine ions. With more bromine ions, better specificity and sensitivity are gained, so it would be preferable for the determination PBDEs with 6 or more bromine atoms. It should be pointed out that even without the help of tandem mass, the performance of GC-NCI-MS surpass GC-El-MS/MS for highly brominated congeners. Nevertheless, in the case of 6'-MeO-BDE99, $\mathrm{NCl}$ provides evidently higher intensity while El presented much better $\mathrm{S} / \mathrm{N}$ ratio. This indicates that tandem mass spectra do avoid interferences and reduce background noise remarkably, benefiting the selectivity when analyzing samples with complicated matrixes. Furthermore, 2'-OH-BDE28 and 2'-MeO-BDE28 have very close retention time, making it impossible to detect 2'-OH-BDE28 by NCl. In contrast, El could separate these two congeners with different selected ion pairs. This revels another advantage of GC-EI-MS/MS, that is, tandem mass could achieve separation for chemically or structurally similar compounds which could not be separated completely. Last but not least, with the sufficient ionization and fragmentation, El Provides detailed structural information such as the molecular weights and the sequential loss of bromine atoms.

To summarize, the choice of ionization source depends on the target PBDE congeners. If highly brominated congeners are the only targets in a simple matrix, GC-NCl-MS would be the best approach as a more commonly accessible instrument. For metabolism, distribution or other studies that require a comprehensive understanding of all PBDE congeners, especially for samples with complicated matrixes, GC-EI-MS/MS would be a better choice.

\subsection{Optimization of SDME}

Based on the above study, GC-EI-MS/MS was selected for the further study on the determination of target PBDE congeners in aqueous samples.

\subsubsection{Optimization of extraction solvents}

The choice of the extraction solvent is crucial for SDME as it greatly affects the enrichment efficiency. It would follow the basis: (a) good solubility for target compounds and water-immiscible; (b) with strong surface tension to maintain a stable extraction drop; (c) without interferences during the instrumental analysis. Therefore, n-hexane, cyclohexane, toluene, xylene and chlorobenzene were selected for the optimization. As shown in Fig. 4, toluene delivers good extraction results for hydroxylated PBDEs while $\mathrm{n}$-hexane would be the first choice for methylated PBDEs. Benefiting from the halogen group and the structural similarity with target PBDE congeners, chlorobenzene demonstrates better extraction results in general. Thus, it was selected for SDME procedure.
Fig. 4 Comparison of different extraction solvents for SDME

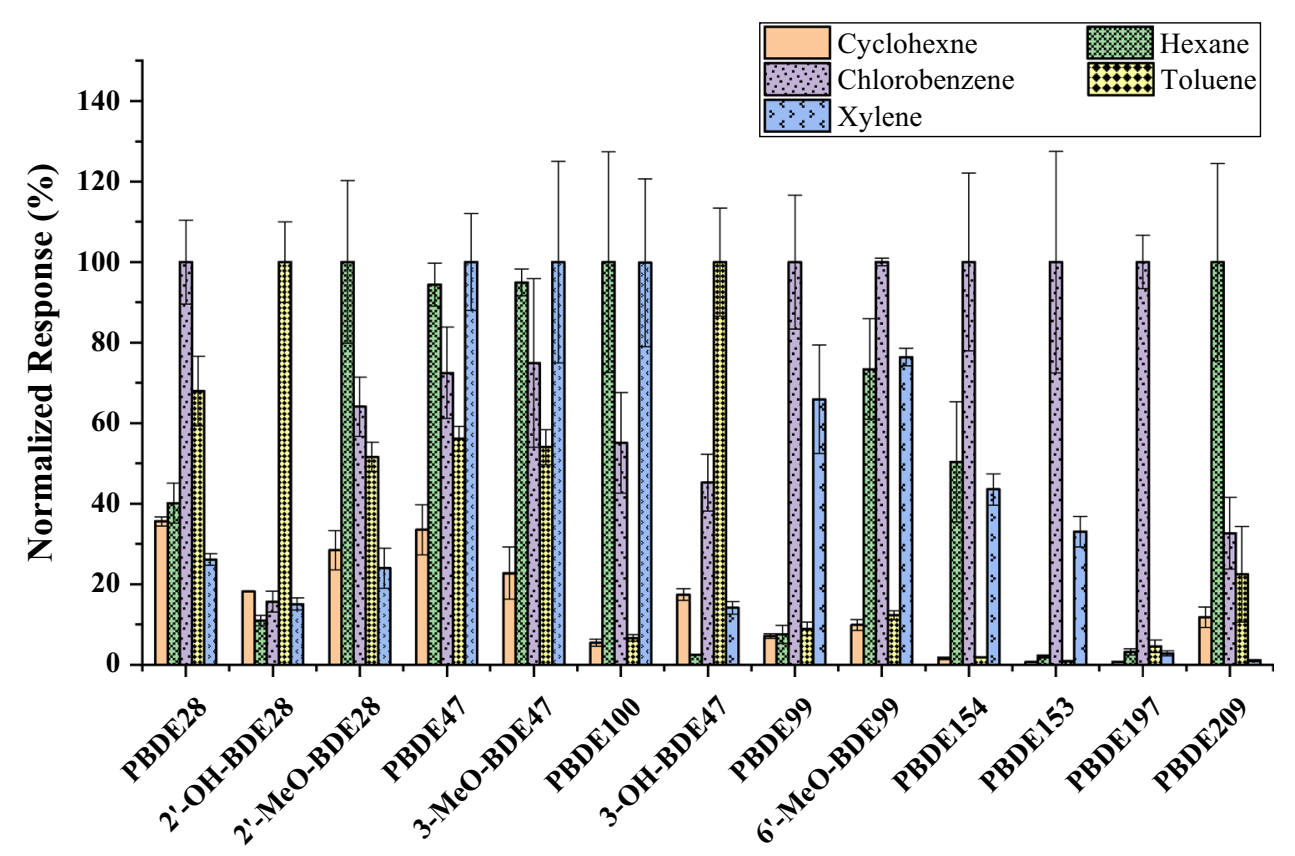




\subsubsection{Optimization of stirring rate}

During the SDME procedure, a suitable stirring rate is important to maximize the mass transfer efficiency. By testing stirring rates from 60 to $600 \mathrm{rpm}$, results demonstrate the optimized stirring rate was $400 \mathrm{rpm}$ (Supplementary Fig. S3). Decrease occurred with a stirring rate of 60 or 200 rpm due to the inefficient mass transfer. Increasing the stirring to $600 \mathrm{rpm}$ might enhance dissolution of the extraction solvents in the aqueous media, which leads to a loss of extractants. The extraction drop became unstable when operated at $800 \mathrm{rpm}$.

\subsubsection{Effects of salinity and pH}

A certain amount of $\mathrm{NaCl}$ was added to adjust the salinity from 0 to $25 \%$ to investigate the effect of ionic strength on the extraction efficiency (Fig. 5a). For highly
Fig. 5 Effect of a salinity and b pH on normalized peak area for PBDE congeners and metabolites
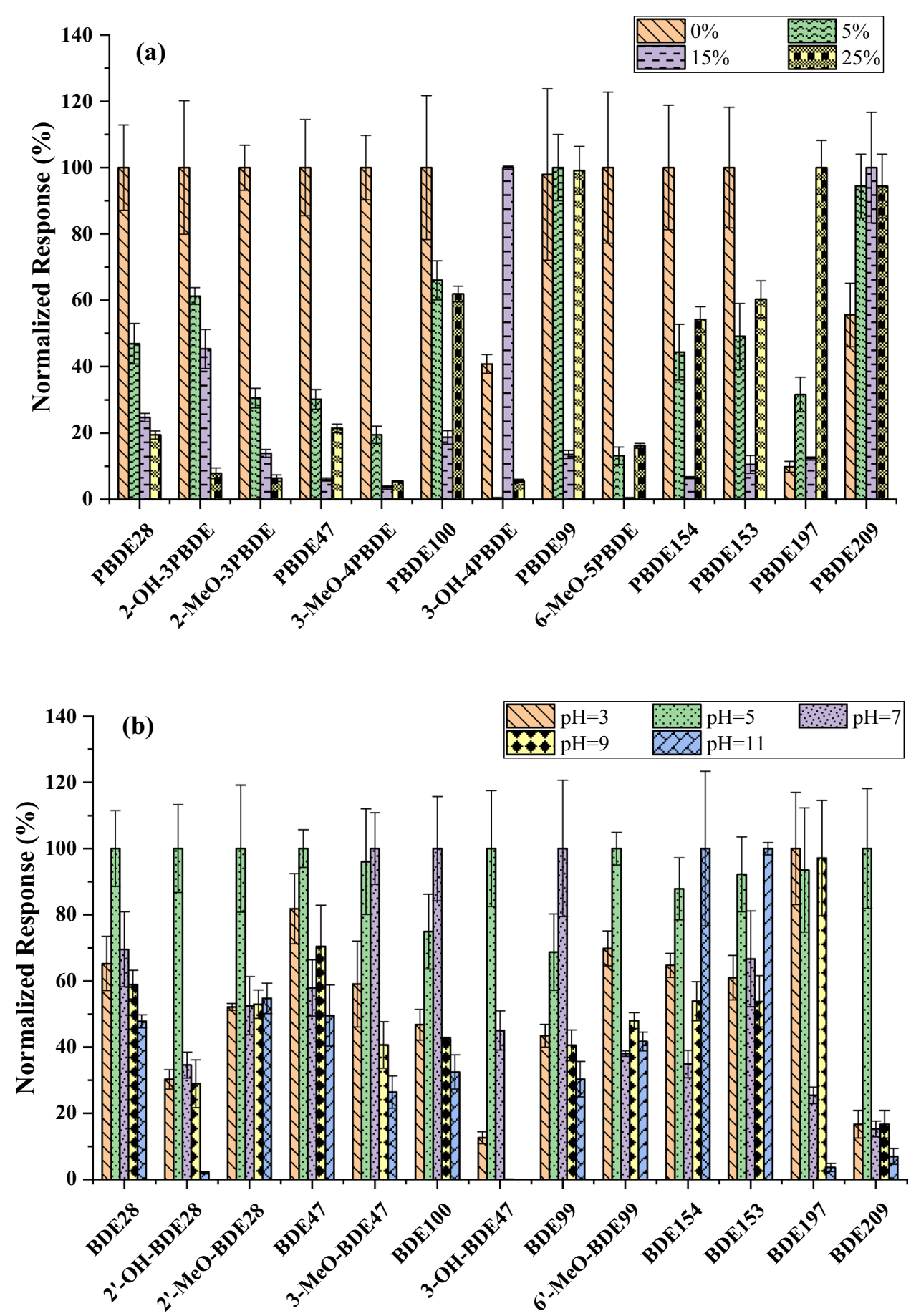
brominated congeners, slight enhancement on extraction was found with $25 \% \mathrm{NaCl}$ because of their decreased solubility in matrixes with strong ionic strength. The extraction of methoxylated or hydroxylated PBDEs on the other hand, was not benefited from the addition of $\mathrm{NaCl}$. The interaction of $\mathrm{NaCl}$ with methoxy group and hydroxy group possibly kept the targets stay in the sample solutions rather than be extracted. In general, the addition of inorganic salts is not necessary for an efficient SDME procedure.

The $\mathrm{pH}$ value of sample was also optimized. From Fig. 5b), the optimum $\mathrm{pH}$ is 5 for most of the target congeners, changing the $\mathrm{pH}$ value draws only slight differences on the extraction of PBDEs.

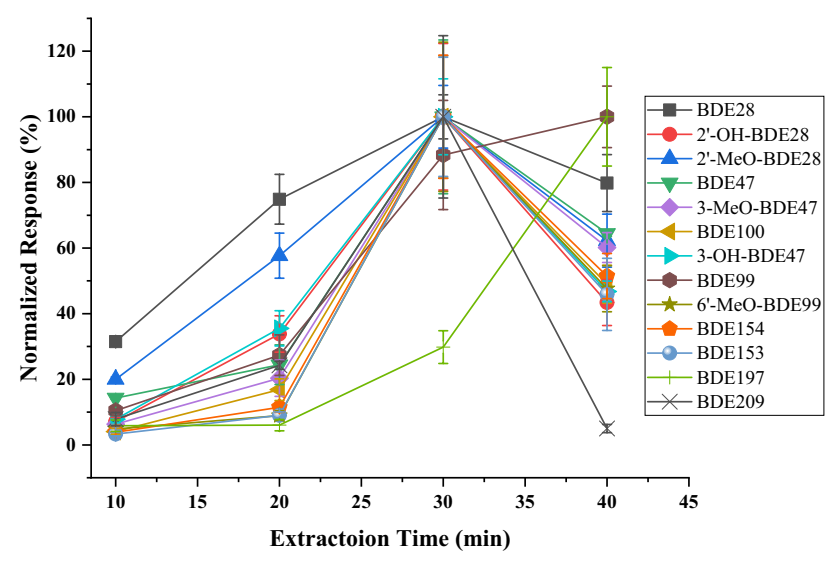

Fig. 6 Effect of SDME extraction time on normalized peak area for PBDE congeners and metabolites

\subsubsection{Effect of extraction time}

The duration of suspending a micro-drop was optimized to achieve sufficient extraction as well as to obtain reasonable sample throughput. Extraction time in the range of 10-40 min was tested. According to the results shown in Fig. 6 , the response of most congeners peaked with an extraction time of $30 \mathrm{~min}$, indicating the equilibrium of extraction has achieved. Extending the extraction time may cause a loss of the extraction solvent. Thirty minutes was chosen as optimum extraction time.

\subsection{Determination of PBDEs congeners in lake water and method validation}

Under the optimized SDME and GC-EI-MS/MS conditions, the linearity of calibration curve, relative standard deviation ( $R S D, n=6)$, limit of detection ( $L O D, S / N=3$ ) and limit of quantification ( $L O Q, S / N=10$ ) were investigated. As shown in Table 2, the linear ranges of all target congeners spanned over 3 orders of magnitudes, and for some lower brominated congeners, achieved 4 orders of magnitudes. The determination coefficients $\left(r^{2}\right)$ ranged from 0.9929 to 0.9998. In comparison with the limits of detection reported by Akerman et al. [25], the resulted sensitivity by SDMEGC-El-MS/MS is much improved.

Real water sample was collected in Southern campus of Sun Yat-sen University. Except for simple filtration, no other pretreatment was required before SDME procedure. Under the optimized conditions, analysis of target PBDE congeners as well as recoveries investigation was carried out. None of target compounds was found in the collected

Table 2 Linear range, LOD, LOQ, RSD and $r^{2}$, recovery and enrichment factor under optimized conditions

\begin{tabular}{|c|c|c|c|c|c|c|c|c|}
\hline \multirow[t]{2}{*}{ PBDE congeners } & \multirow[t]{2}{*}{ Linear range $\left(\mu \mathrm{g} \mathrm{L}^{-1}\right)$} & \multirow{2}{*}{$\begin{array}{l}\text { Determination } \\
\text { coefficient }\left(r^{2}\right)\end{array}$} & \multirow[t]{2}{*}{$\operatorname{LOD}\left(\mu \mathrm{g} \mathrm{L}^{-1}\right)$} & \multirow[t]{2}{*}{$\mathrm{LOQ}\left(\mu \mathrm{g} \mathrm{L}^{-1}\right)$} & \multicolumn{4}{|l|}{ Lake water } \\
\hline & & & & & $\begin{array}{l}\text { Spiked } \\
\text { concentration } \\
\left(\mu \mathrm{g} \cdot \mathrm{L}^{-1}\right)\end{array}$ & Recovery (\%) & RSD (\%) & $\begin{array}{l}\text { Enrich- } \\
\text { ment } \\
\text { factor }\end{array}$ \\
\hline BDE28 & $0.001-1$ & 0.9998 & $0.14 \times 10^{-4}$ & $0.45 \times 10^{-4}$ & 0.02 & 88.7 & 16.3 & 15 \\
\hline 2'-OH-BDE28 & $0.001-1$ & 0.9986 & $0.40 \times 10^{-4}$ & $0.13 \times 10^{-3}$ & 0.02 & 119 & 10.9 & 52 \\
\hline 2'-MeO-BDE28 & $0.001-0.1$ & 0.9929 & $0.20 \times 10^{-4}$ & $0.63 \times 10^{-4}$ & 0.02 & 128 & 8.06 & 60 \\
\hline BDE47 & $0.001-0.5$ & 0.9970 & $0.30 \times 10^{-4}$ & $0.11 \times 10^{-3}$ & 0.02 & 107 & 7.52 & 12 \\
\hline 3-MeO-BDE47 & $0.001-1$ & 0.9995 & $0.43 \times 10^{-3}$ & $1.4 \times 10^{-3}$ & 0.02 & 74.7 & 20.4 & 24 \\
\hline BDE100 & $0.01-10$ & 0.9933 & $3.3 \times 10^{-3}$ & $11 \times 10^{-3}$ & 8.00 & 90.0 & 14.2 & 32 \\
\hline 3-OH-BDE47 & $0.01-10$ & 0.9998 & $0.27 \times 10^{-3}$ & $0.88 \times 10^{-3}$ & 8.00 & 130 & 21.2 & 41 \\
\hline BDE99 & $0.01-5$ & 0.9997 & $5.7 \times 10^{-3}$ & $19 \times 10^{-3}$ & 0.20 & 70.7 & 21.4 & 24 \\
\hline 6'-MeO-BDE99 & $0.01-5$ & 0.9997 & $6.0 \times 10^{-3}$ & $20 \times 10^{-3}$ & 0.20 & 101 & 25.0 & 25 \\
\hline BDE154 & $0.1-50$ & 0.9996 & $25 \times 10^{-3}$ & $83 \times 10^{-3}$ & 2.00 & 73.4 & 4.17 & 15 \\
\hline BDE153 & $0.1-50$ & 0.9988 & $14 \times 10^{-3}$ & $45 \times 10^{-3}$ & 2.00 & 71.8 & 15.9 & 13 \\
\hline BDE197 & $1-100$ & 0.9983 & 0.30 & 1.1 & 2.00 & 98.7 & 13.3 & 12 \\
\hline BDE209 & $20-1000$ & 0.9991 & 6.0 & 20 & 20.00 & 100 & 17.3 & 8 \\
\hline
\end{tabular}


lake water. For recoveries experiment, the lake water was spiked with target compounds with different concentration. As the presented in Table 2, the recoveries ranged from 74.7 to $130 \%$, and the enrichment factors (calculated as the ratio of calibration slope with and without SDME) ranged from 8 to 60 , indicating the SDME treatment is relatively stable and sufficient for PBDEs detection. The $\operatorname{RSD}(n=6)$ varies upon congeners, ranging from $4.17 \%$ to $25.00 \%$, which reveals the decent precision and reproducibility of GC-EI-MS/MS.

\section{Conclusions}

The present study developed the single-drop microextraction, coupling with gas chromatography-tandem mass spectrometry for the determination of PBDE congeners and their metabolites in water samples. By optimizing high mass fragment ion abundance over a range of El parameters, GC-El-MS/MS provides better identification between congeners. In addition, the use of tandem mass delivers better $\mathrm{S} / \mathrm{N}$ ratio, which enables the congener-specific analysis in complicated matrixes. In comparison, GC-NCIMS is more suitable for the analysis of highly brominated PBDEs. The single-drop microextraction has been proved to be a simple, fast and one-step extraction technique, coupling with GC, for PBDEs determination in aqueous samples. With the optimization over the extraction conditions, reliable quantification of 13 PBDE congeners in real water samples has been achieved with satisfied precision and sensitivity.

Acknowledgements Financial support from the National Natural Science Foundation of China (NSFC, No. 41271505) is gratefully acknowledged.

Data availability We declared that materials described in the manuscript, including all relevant raw data, will be freely available to any scientist wishing to use them for non-commercial purposes, without breaching participant confidentiality.

\section{Compliance with ethical standards}

Conflicts of interest We declare that we do not have any commercial or associative interest that represents a conflict of interest in connection with the work submitted.

\section{References}

1. Rahman F, Langford KH, Scrimshaw MD, Lester JN (2001) Polybrominated diphenyl ether (PBDE) flame retardants. Sci Total Environ 275:1-17

2. U.S. Department of Health and Human Services (2004) Toxicological profile for polybrominated biphenyls and polybrominated diphenyl ethers. https://www.atsdr.cdc.gov/ toxprofiles/tp68.pdf

3. U.S. Environmental Protection Agency (2014) Technical Fact Sheet-Polybrominated Diphenyl Ethers (PBDEs) and Polybrominated Biphenyls (PBBs). https://www.epa.gov/sites/produ ction/files/2014-03/documents/ffrrofactsheet_contaminan t_perchlorate_january2014_final_0.pdf

4. Directorate-General ECH\& CP (2010) Opinion on "Chemicals and the water framework directive: draft environmental quality standards" PBDE. https://ec.europa.eu/health/scientific _committees/environmental_risks/docs/scher_o_127.pdf

5. Siddiqi MA, Clinic M (2003) Polybrominated Diphenyl ethers (PBDEs): new pollutants-old diseases. Clin Med Res 1:281-290

6. Darnerud PO, Eriksen GS, Jóhannesson T et al (2001) Polybrominated diphenyl ethers : occurrence, dietary exposure, and toxicology. Environ Health Perspect 109:49-68

7. Viberg H, Fredriksson A, Jakobsson E et al (2003) Neurobehavioral derangements in adult mice receiving decabrominated diphenyl ether (PBDE 209) during a defined period of neonatal brain development. Toxicol Sci 76:112-120. https://doi. org/10.1093/toxsci/kfg210

8. Viberg H, Fredriksson A, Eriksson P (2004) Investigations of strain and/or gender differences in developmental neurotoxic effects of polybrominated diphenyl ethers in mice. Toxicol Sci 81:344-353. https://doi.org/10.1093/toxsci/kfh215

9. Hallgren S, Sinjari T, Håkansson H, Darnerud P (2001) Effects of polybrominated diphenyl ethers (PBDEs) and polychlorinated biphenyls (PCBs) on thyroid hormone and vitamin $A$ levels in rats and mice. Arch Toxicol 75:200-208. https://doi. org/10.1007/s002040000208

10. Zhou T (2001) Effects of Short-term in vivo exposure to polybrominated diphenyl ethers on thyroid hormones and hepatic enzyme activities in weanling rats. Toxicol Sci 61:76-82. https ://doi.org/10.1093/toxsci/61.1.76

11. Zhou T (2002) Developmental exposure to brominated diphenyl ethers results in thyroid hormone disruption. Toxicol Sci 66:105-116. https://doi.org/10.1093/toxsci/66.1.105

12. Legler J, Brouwer A (2003) Are brominated flame retardants endocrine disruptors? Environ Int 29:879-885. https://doi. org/10.1016/S0160-4120(03)00104-1

13. Darnerud PO (2008) Brominated flame retardants as possible endocrine disrupters. Int J Androl 31:152-160. https://doi.org /10.1111/j.1365-2605.2008.00869.x

14. Branchi I, Capone F, Alleva E, Costa LG (2003) Polybrominated diphenyl ethers: neurobehavioral effects following developmental exposure. Neurotoxicology 24:449-462. https://doi. org/10.1016/S0161-813X(03)00020-2

15. Cancer IA for R on (2018) Agents classified by the IARC monographs, Volumes 1-111.1-35. https://monographs.iarc.fr/wpcontent/uploads/2018/09/ClassificationsAlphaOrder.pdf

16. Agency USEP (2008) Toxicological review of decabromodiphenyl ether (BDE-209). https://cfpub.epa.gov/ncea/iris/ iris_documents/documents/toxreviews/0035tr.pdf

17. Hardell L, Lindström G, van Bavel B et al (1998) Concentrations of the flame retardant 2,2,4,4'-tetrabrominated diphenyl ether in human adipose tissue in Swedish persons and the risk for non-Hodgkin's lymphoma. Oncol Res 10:429-432

18. Huang SC, Giordano G, Costa LG (2010) Comparative cytotoxicity and intracellular accumulation of five polybrominated diphenyl ether congeners in mouse cerebellar granule neurons. Toxicol Sci 114:124-132. https://doi.org/10.1093/toxsci/ kfp296

19. Hu X-Z, Xu Y, Hu D-C et al (2007) Apoptosis induction on human hepatoma cells Hep G2 of decabrominated diphenyl ether (PBDE-209). Toxicol Lett 171:19-28. https://doi.org/10.1016/j. toxlet.2007.04.002 
20. Roze E, Meijer L, Bakker A et al (2009) Prenatal exposure to organohalogens, including brominated flame retardants, influences motor, cognitive, and behavioral performance at school age. Environ Health Perspect 117:1953-1958. https://doi. org/10.1289/ehp.0901015

21. Johansson N, Viberg H, Fredriksson A, Eriksson P (2008) Neonatal exposure to deca-brominated diphenyl ether (PBDE 209) causes dose-response changes in spontaneous behaviour and cholinergic susceptibility in adult mice. Neurotoxicology 29:911-919. https://doi.org/10.1016/j.neuro.2008.09.008

22. Agency USEP (2010) Method 1614 brominated diphenyl ethers in water soil, sediment and tissue by HRGC/HRMS. https://www. epa.gov/sites/production/files/2015-08/documents/metho d_1614a_2010.pdf

23. Wang D, Cai Z, Jiang G et al (2005) Determination of polybrominated diphenyl ethers in soil and sediment from an electronic waste recycling facility. Chemosphere 60:810-816. https://doi. org/10.1016/j.chemosphere.2005.04.025

24. Covaci A, de Boer J, Ryan JJ et al (2002) Determination of polybrominated diphenyl ethers and polychlorinated biphenyls in human adipose tissue by large-volume injection-narrow-bore capillary gas chromatography/electron impact low-resolution mass spectrometry. Anal Chem 74:790-798. https://doi. org/10.1021/ac010784e

25. Ackerman LK, Wilson GR, Simonich SL (2005) Quantitative analysis of 39 polybrominated diphenyl ethers by isotope dilution GC/low-resolution MS. Anal Chem 77:1979-1987

26. Hites RA (2008) Electron Impact and electron capture negative ionization mass spectra of polybrominated diphenyl ethers and methoxylated polybrominated diphenyl ethers. Environ Sci Technol 42:2243-2252. https://doi.org/10.1021/es072064g

27. Thomsen C, Sm L, Leknes $\mathrm{H}$ et al (2002) Comparing electron ionization high-resolution and electron capture low-resolution mass spectrometric determination of polybrominated diphenyl ethers in plasma, serum and milk. Chemosphere 46:641-648

28. Gómara B, Herrero L, González MJ (2007) Feasibility of electron impact and electron capture negative ionisation mass spectrometry for the trace determination of tri- to deca-brominated diphenyl ethers in human samples. Anal Chim Acta 597:121128. https://doi.org/10.1016/j.aca.2007.06.037

29. Wen Q, Liu H-L, Su G-Y et al (2012) Determination of polybrominated diphenyl ethers and their derivates in Zebrafish eggs. Chin J Anal Chem 40:1698-1702. https://doi.org/10.1016/S1872 -2040(11)60587-2

30. Barri T, Bergstr S, Ake J (2006) Determination of polybrominated diphenyl ethers at trace levels in environmental waters using hollow-fiber microporous membrane liquid-liquid extraction and gas chromatography-mass spectrometry. J Chromatogr A 1133:41-48. https://doi.org/10.1016/j.chroma.2006.08.026

31. Ohta S, Ishizuka D, Nishimura $\mathrm{H}$ et al (2002) Comparison of polybrominated diphenyl ethers in fish, vegetables, and meats and levels in human milk of nursing women in Japan. Chemosphere 46:689-696. https://doi.org/10.1016/S0045-6535(01)00233-8

32. Thomsen C, Lundanes E, Becher G (2001) Brominated flame retardants in plasma samples from three different occupational groups in Norway. J Environ Monit 3:366-370. https:// doi.org/10.1039/b104304h
33. Thomsen C, Lundanes E, Becher G (2001) A simplified method for determination of tetrabromobisphenol $A$ and polybrominated diphenyl ethers in human plasma and serum. J Sep Sci 24:282-290. https://doi.org/10.1002/1615-9314(20010 401)24:4\%3c282:AID-JSSC282\%3e3.0.CO;2-D

34. Wang J-X, Jiang D-Q, Gu Z-Y, Yan X-P (2006) Multiwalled carbon nanotubes coated fibers for solid-phase microextraction of polybrominated diphenyl ethers in water and milk samples before gas chromatography with electron-capture detection. J Chromatogr A 1137:8-14. https://doi.org/10.1016/j.chrom a.2006.10.003

35. Polo M, Gómez-Noya G, Quintana JB et al (2004) Development of a solid-phase microextraction gas chromatography/tandem mass spectrometry method for polybrominated diphenyl ethers and polybrominated biphenyls in water samples. Anal Chem 76:1054-1062. https://doi.org/10.1021/ac030292x

36. Psillakis E, Kalogerakis N (2002) Developments in single-drop microextraction. TrAC Trends Anal Chem 21:54-64. https://doi. org/10.1016/S0165-9936(01)00126-1

37. Przyjazny A, Kokosa JM (2002) Analytical characteristics of the determination of benzene, toluene, ethylbenzene and xylenes in water by headspace solvent microextraction. J Chromatogr A 977:143-153. https://doi.org/10.1016/S0021-9673(02)01422 $-\mathrm{X}$

38. Khajeh M, Yamini Y, Hassan J (2006) Trace analysis of chlorobenzenes in water samples using headspace solvent microextraction and gas chromatography/electron capture detection. Talanta 69:1088-1094. https://doi.org/10.1016/j.talan ta.2005.12.020

39. Bagheri H, Saber A, Mousavi SR (2004) Immersed solvent microextraction of phenol and chlorophenols from water samples followed by gas chromatography-mass spectrometry. J Chromatogr A 1046:27-33. https://doi.org/10.1016/j.chrom a.2004.06.062

40. Saraji M, Bakhshi M (2005) Determination of phenols in water samples by single-drop microextraction followed by insyringe derivatization and gas chromatography-mass spectrometric detection. J Chromatogr A 1098:30-36. https://doi. org/10.1016/j.chroma.2005.08.063

41. Kawaguchi $\mathrm{M}$, Ito R, Endo $\mathrm{N}$ et al (2006) Liquid phase microextraction with in situ derivatization for measurement of bisphenol $A$ in river water sample by gas chromatography-mass spectrometry. J Chromatogr A 1110:1-5. https://doi.org/10.1016/j. chroma.2006.01.061

42. Jeannot MA, Cantwell FF (1997) Mass Transfer characteristics of solvent extraction into a single drop at the tip of a syringe needle. Anal Chem 69:235-239. https://doi.org/10.1021/ac960 $814 r$

Publisher's Note Springer Nature remains neutral with regard to jurisdictional claims in published maps and institutional affiliations. 